\title{
Training overseas graduates in neonatal intensive care
}

\author{
Neena Modi
}

Each year large numbers of medical graduates from the Indian subcontinent arrive in the UK seeking further training and experience in neonatal intensive care. Most of these doctors are certain that they wish ultimately to return to practice in their own country. How is British training perceived abroad and how well do the experiences of overseas doctors prepare them for practice on their return home? A recent visit to India through a British Paediatric Association/Heinz fellowship allowed some observations to be made.

Neonatal intensive care is a relatively new specialty and so Indian paediatricians tend to travel to Australia, the UK or to the United States, to further their experience. Increasingly, the United States is the favoured option, because of structured training and formal certification. The Royal College of Physicians' Overseas Doctors Training Scheme is regarded unfavourably because placements, certainly in neonatal paediatrics, are few and the prolonged period of uncertainty makes forward planning virtually impossible. Indeed, by raising expectations which are unlikely to be fulfilled, the scheme, in its present form, may be doing the image of British medical training more harm than good.

In the UK, the lack of formal training programmes means that the usual route towards acquiring experience and training in neonatal medicine is through a senior house officer or registrar post. These offer exposure to high technology neonatal medicine in institutions with skilled nursing staff and dependable laboratory and paramedical support. Junior doctors may become expert in the use of intensive care equipment but maintenance is carried out by professional technicians. Overseas graduates learn how Western society copes with the ethical dilemmas that are commonplace in neonatal intensive care. On their return home they are faced with having to put what they have learnt into practice under very different circumstances.

India is a hugely crowded country and one in which death in infancy is still not uncommon. In 1991 India's population was 844 million. The birth rate (1988) is around $31.5 / 1000$; the infant mortality rate variable, from $62 / 1000$ in urban areas to 102 in rural areas, at its lowest $28 / 1000$ in Kerala, rising to 124 in Uttar Pradesh. ${ }^{1}$ Social attitudes and values are not necessarily those of the West.
Female infants remain undervalued and often unwanted. Female infanticide still occurs. This year the state government of Karnataka instituted a scheme allowing unwanted female infants to be handed in to a state orphanage. Other traditional beliefs, alternative systems of medicine - Ayurvedic, Unnani - jostle uneasily with those of the West. In India the heartrendingly poor exist side by side with the astoundingly rich. Health insurance is virtually unknown. The concept of attempting to defy the vissicitudes of fate through insurance is not one that is at home in the East. Private medicine flourishes. Doctors hold high status but that status is commensurate with their wealth, not with their position.

The country has a shaky medical support infrastructure. Power cuts and voltage fluctuations are commonplace and an in-house generator and voltage stabilisers are essential. Certain intensive care equipment is now made by Indian firms but they need to establish a reputation for reliability and back up. To import equipment means to accept hugely cumbersome and often frankly obstructive bureaucratic paperwork with seemingly insurmountable delays. Skilled neonatal nurses are hard to find. Poor pay and poor professional status lead many to seek better rewards in the Middle East. Government legislation promotes national pharmaceuticals and thus keeps costs down but many drugs are therefore unavailable or prohibitively expensive.

Births take place in government hospitals, private nursing homes, or at home. Neonatal care over and above routine care is available in very few institutions and these are, on the whole, fee charging. If a neonatal problem arises there is very often little that can be done but if the baby is referred elsewhere it is up to the family to organise the transfer. All too often this is by open autorickshaw, or threewheeler, and outborn admissions to neonatal units invariably arrive cold. Ambulance services are scanty, virtually non-existent. Once the baby has been assessed, the family must decide whether they can afford treatment. Drugs, blood, disposables, diagnostic tests, therapeutic procedures, physicians' fees, all are individually charged. All too often the family must physically purchase drugs and blood themselves. Many opt not to accept treatment and the baby is left or taken home to die. 
The difficulties of practising neonatal medicine in India may be known but they are unlikely to be appreciated without having been experienced. Two way exchanges of junior medical staff are likely to be of mutual benefit. Regrettably this is a rare event, but it perhaps offers another opportunity to improve the image of British medical training. Further, if we in Britain aspire to offer training in neonatal intensive care we must pay heed to the conditions under which returning students will practice. It is both patronising and unrealistic to dismiss the issue by saying that there is no place for neonatal intensive care in the developing world. In the face of her problems India's achievements are already enormous and put those of the West into stark, and relatively trivial, perspective. Rather, the challenge is to determine what are the most appropriate treatment methodologies, given these problems. It is useless to advise the use of surfactant for respiratory distress syndrome in a country where it is not available; it is harmful to advocate low birthweight formulas in a country where maternal lactation is so much more successful than in the West and where diarrhoeal disease is still widespread. I suggest that more could be done to encourage the evaluation of alternative but appropriate strategies for neonatal care in the developing world. Examples abound: a well designed nursery, aimed at making the best use of natural light, ${ }^{2}$ is as important as the use of expensive phototherapy machines; in the management of respiratory distress syndrome, the most cost effective, proved treatment strategy is the antenatal use of steroids ${ }^{3}$ and the implementation of their use, as institutional policy, should take precedence over the purchase of a neonatal ventilator; the early use of continuous positive airway pressure substantially reduces the need for ventilation ${ }^{4}$ and is both less expensive and less technically demanding. Further, in so rapidly changing a field as neonatal intensive care, training should, without doubt, include how to evaluate quality of care and how to assess the outcome of a treatment or management policy.

At present, it is all too often the case that promising young men and women, sent abroad to further their training, fail to cope with the realities of life 'back home' and flee back to the West to practise as they were trained to do. Perhaps more heed should be paid to what faces them and the question 'How would you manage this problem at home?' asked more often.

1 Banerji D. Population growth, development and family planning in India. National Medical fournal of India 1992; 5: $182-4$.

2 Barss P, Comfort K. Ward design and neonatal jaundice in the tropics: report of an epidemic. $B M F$ 1985; 291: 400-1.

3 Crowley P, Chalmers I, Keirse MINC. The effects of corticosteroid administration before preterm delivery: an overview of the evidence from controlled trials. Br $\mathfrak{f}$ Obstet Gynaecol 1990; 97: 11-25.

4 Bancalari E, Sinclair J. Mechanical ventilation. In: Sinclair JC, Bracken MB, eds. Effective care of the newborn infant. Oxford: Oxford University Press, 1992: 202-3. 